\title{
Intravenous Dexamethasone as an Adjuvant to Caudal Analgesia for Post Herniotomy Pain
}

\author{
MUHAMMAD SHARIF ${ }^{1}$, MUHAMMAD ARIF BALOCH ${ }^{2}$, NAZEER AHMED ${ }^{3}$, ZAFARULLAH $^{4}$, YASIR REDA TOBLE ${ }^{5}$ \\ ${ }^{1}$ Registrar Anesthesia, Lateefa Hospital Dubai. \\ ${ }^{2}$ Specialist Anesthetist, Hamad Medical Corporation (HMC) Qatar. \\ ${ }^{3}$ Associate Consultant Anesthetist, Hamad Medical Corporation (HMC), Qatar. \\ ${ }^{4}$ FCPS \\ ${ }^{5}$ Senior consultant Anesthetist, HMC Qatar. \\ Correspondence to: Arif Baloch, Email: marifbaloch@gmail.com
}

\begin{abstract}
Objective: To compare the outcomes of caudal block with or without intravenous dexamethasone in controlling post-herniotomy pain in pediatric population

Patients and Methods: A total of 90 patients who underwent inguinal herniotomy were included in this prospective comparative study. The study was conducted in a tertiary care setup in Qatar from Jan-2020 to May2021. Patients were randomly allocated to two groups. Group A (dexamethasone) patients received dexamethasone intravenous $0.25 \mathrm{mg} / \mathrm{kg}$ in $5 \mathrm{ml}$ of distilled water, 10 minutes before surgery. Group B (control) received $5 \mathrm{ml}$ of normal saline, 10 minutes before surgery. The patients were followed for up to 240 minutes after surgery to determine adequate pain relief.

Results: Mean age of the children included in this study was $7.11 \pm 1.95$ years. There were $46(51.1 \%)$ female children and 44 (48.9\%) male children. Adequate post-operative pain relief was achieved in $30(33.33 \%)$ patients, while rescue analgesia was needed in remaining $60(66.67 \%)$ patients. Adequate pain relief was achieved in 24 (53.3\%) children in dexamethasone group and in only 06 (13.3\%) children in control group (p-value 0.001$)$.

Conclusion: In children undergoing herniotomy, Intravenous $0.25 \mathrm{mg} / \mathrm{Kg}$ of dexamethasone when used as an adjunct to bupivacaine for caudal block significantly reduces post-operative pain.

Keywords: Caudal Block, intravenous dexamethasone, Post-operative pain Relief.
\end{abstract}

\section{INTRODUCTION}

Pain after surgery adversely effects health outcomes. ${ }^{1}$ Untreated pain may have long-term deleterious impacts on pain sensitivity, immunological function, neurophysiology, attitudes, and health-care behavior, according to evidence. ${ }^{2}$ When compared to adults, postoperative pain in children was mostly disregarded or undertreated in the 1970s and 1980s. ${ }^{3}$ This has been shown to have substantial consequences for children both in the immediate postoperative time and in the extended postoperative term. As a result, diagnosing, monitoring, and treating pain in children is critical. ${ }^{4}$

According to reports, up to $40 \%$ of children who have surgery experience moderate to severe post-operative pain. ${ }^{5}$ Almost all treatments involving the lower abdomen and lower limbs need caudal anesthesia for pre- and postoperative analgesia, particularly in newborns and young children. ${ }^{6}$ In pediatric patients, a caudal epidural block is a typical regional approach for providing intra- and postoperative analgesia for surgical operations below the umbilicus. ${ }^{7}$ It's often a one-shot approach. The procedure's shortcomings include the procedure's very brief duration of single-shot caudal injection with local anesthetic. ${ }^{8}$ Clonidine, midazolam, ketamine, neostigmine, and tramadol are some of the adjuncts that have been added to local anesthetics to prolong analgesia of single-shot' caudal analgesia, but their use has been limited due to unacceptable side effects or safety concerns, especially in preservative-containing agents. ${ }^{9}$ Dexamethasone is a corticosteroid that has powerful anti-inflammatory effects. ${ }^{10}$ Dexamethasone has traditionally been used in anesthetic treatment to lower the occurrence of post-operative nausea and vomiting (PONV). When given intravenously, dexamethasone has been shown to offer sustained postoperative analgesia7. When paired with a caudal block, intravenous dexamethasone has been shown to improve postoperative analgesia. The aim of this study was to compare the outcomes of caudal block with or without intravenous dexamethasone in controlling post-herniotomy pain in pediatric population.

\section{MATERIAL AND METHODS}

A total of 90 patients who underwent herniotomy were included in this prospective comparative study. The study was conducted in a tertiary care setup in Qatar from Jan2020 to May-2021. Patients of age 4-10 years, with ASA status I-II, having inguinal hernia were included. Patients with coagulation disorders as deranged PT, APTT values, INR $>1.5$, pre-existing neurological disease like cerebral palsy (CP), and spine abnormalities or any infection at the local site were excluded. Approval from ethical committee of the hospital was taken.

Patients were randomly allocated in to two groups by lottery method. We used $0.25 \%$ Bupivacaine $(1 \mathrm{ml} / \mathrm{kg}), 10$ minutes before surgery as caudal analgesia in all patients of both groups. Group A (dexamethasone) patients received dexamethasone intravenous $0.25 \mathrm{mg} / \mathrm{kg}$ in $5 \mathrm{ml}$ of distilled water, 10 minutes before surgery and note the response in terms of pain relief after the end of surgery up to 240 minutes. Group B (control) received $5 \mathrm{ml}$ of normal saline, 10 minutes before surgery and note the response in terms of pain relief after the end of surgery up to 240 minutes.

At the end of surgery post-operative pain was assessed by the resident anesthetist neither involved in study nor in the surgical procedure and recorded in both 
groups at post-anesthesia care unit (PACU), using the Visual Analogue Scale (VAS) as defined in operational definition. The effectiveness (in terms of pain relief) (yes/No) was noted for each patient. The patients having score $<3$, up to 240 minutes after the end of surgery was considered as having adequate pain relief.

All data was entered using software SPSS version 21. Mean and standard deviation was calculated for age and BMI. Frequencies and percentages was calculated for gender, residential status, and pain relief in both groups. Chi-square test was applied to compare the outcome (pain relief) in both groups at $p$ value of $\leq 0.05$ as significant.

\section{RESULTS}

Mean age of the children included in this study was $7.11 \pm 1.95$ years. Mean BMl of study children was $23.41 \pm 2.66 \mathrm{Kg} / \mathrm{m}^{2}$. Minimum BMl was $18.70 \mathrm{Kg} / \mathrm{m}^{2}$ and maximum BMI was $31.10 \mathrm{Kg} / \mathrm{m}^{2}$. There were $46(51.1 \%)$ female children and 44 (48.9\%) male children in this study.

Adequate post-operative pain relief was achieved in $30(33.33 \%)$ patients, while rescue analgesia was needed in remaining $60(66.67 \%)$ patients. On comparison of Adequate post-operative pain relief between the groups, adequate pain relief was found in 24 (53.3\%) children in dexamethasone group and in only 06 (13.3\%) children in control group (p-value 0.001) [Table 1].

Table 1. Comparison of Post-Operative Pain Relief Between the Groups.

\begin{tabular}{|l|l|l|l|}
\hline Pain Relief & \multicolumn{2}{|l|}{ Study Groups } & \multirow{2}{*}{ P-value } \\
\cline { 2 - 3 } & $\begin{array}{l}\text { Dexamethasone } \\
\text { (Group A) }\end{array}$ & $\begin{array}{l}\text { Normal Saline } \\
\text { (Group B) }\end{array}$ & \\
\hline Yes & $24(53.3 \%)$ & $06(13.3 \%)$ & $<0.001$ \\
\hline No & $21(46.7 \%)$ & $39(86.7 \%)$ & \\
\hline
\end{tabular}

\section{DISCUSSION}

Caudal blocking, sometimes known as "the single most significant pediatric regional anesthetic technique," is an effective and safe way to provide surgical anaesthetic and postoperative analgesia for children's lower abdomen surgeries. ${ }^{11}$ The length of analgesia from the block, which is usually provided as a single injection, is a constraint. As a result, there has been a lot of interest in so-called adjuvants, or drugs that extend the length of the block. Dexamethasone is one such adjuvant, and it has been shown to prolong the duration of peripheral nerve blocks when administered through both the intravenous (IV) and perineural routes. ${ }^{12}$ Dexamethasone is routinely used to alleviate surgical nausea and vomiting during the perioperative phase. It has also been reported to have analgesic properties. ${ }^{13}$ Several studies have recently shown that administering dexamethasone by epidural injection prolongs analgesic effects and reduces analgesic needs in adults. ${ }^{14}$ Dexamethasone was also used as an adjuvant to local anaesthetics during brachial plexus block, which increased the quality of analgesia without causing any adverse effects. Dexamethasone is thought to have anti-inflammatory characteristics as well as a direct impact on nociceptive fibers. ${ }^{15}$

In present study we evaluated the analgesic efficacy of intravenous administration of $025 \mathrm{mg} / \mathrm{Kg}$ of dexamethasone as an adjunct to bupivacaine in children undergoing herniotomy. We found significant beneficial effect of dexamethasone in reduction of post-operative pain. In our study, post-operative pain relief was found in $53.3 \%$ children in whom dexamethasone was given and in only $13.3 \%$ children in whom dexamethasone was not given.

A study conducted by Kim et al. found significant pain relief in $50 \%$ patients after 48 hours of surgery and in only $10.8 \%$ of the patients in normal saline group. ${ }^{16}$ That is similar to the results of our study.

In the study of Bangash et al. the mean duration of analgesia was $621.60 \pm 25.74$ minutes and $402.40 \pm 34.79$ minutes in group A (with dexamethasone) and group $B$ (with normal saline) respectively. ${ }^{17}$

A most recent study used $0.1 \mathrm{mg} / \mathrm{kg}$ of dexamethasone with caudal block in children undergoing herniotomy and find $50 \%$ pain relief in dexamethasone group than control group as $10.7 \% .^{18}$

The dose of dexamethasone employed in this study was half that used by Hong et al. in their study in order to find out if this dose can adequately prolong analgesia, and for how long. There is paucity of studies investigating intravenous dexamethasone combined with caudal or other neuraxail blocks. Also there is lack of dosage standardization regarding the use of intravenous dexamethasone for analgesia in children. ${ }^{19}$

Intravenous dexamethasone has improved duration of analgesia with other types of blocks. Desmet et al. in a randomized placebo-controlled study, reported statistically significant difference $(p<0.0001)$ in the time to first analgesic request in adults that had intravenous dexamethasone in addition to interscalene brachial plexus block compared to control group. ${ }^{20}$

Also, a systematic review and meta-analysis of RCT involving perineural dexamethasone in addition to local anaesthetic agents, compared with local anaesthetic alone for brachial plexus block by Choi et al, obtained a longer analgesic duration in the dexamethasone group (1306 min) compared with the local anaesthetic only group (730 $\mathrm{min}){ }^{21}$

We didn't look at some of dexamethasone's possible side effects, such as hyperglycemia and adrenal suppression, in this research. Actually we did not want to employ invasive procedures for blood drawing since the children who had a day-case herniotomy do not need postoperative laboratory tests. Previous research has shown, however, that a single little dosage of dexamethasone does not cause substantial adverse effects.

\section{CONCLUSION}

In children undergoing herniotomy, Intravenous $0.25 \mathrm{mg} / \mathrm{Kg}$ of dexamethasone when used as an adjunct to bupivacaine for caudal block significantly reduces post-operative pain.

\section{REFERENCES}

1. Cinar SO, Isil CT, Sahin SH, Paksoy I. Caudal ropivacaine and bupivacaine for postoperative analgesia in infants undergoing lower abdominal surgery. Pak J Med Sci. 2015;31(4):903-8.

2. Young KD. Pediatric procedural pain. Ann Emerg Med. 2005; 45:160-71.

3. Abd-Elshafy SK, Yacoup AM, Abdalla EE, El-Melegy TT, Abd-Elsalam KA. A new look on adding dexamethasone 
as an adjuvant to caudal bupivacaine; efficacy on postoperative pain and vomiting in pediatric patients. Pain Physician. 2016;19:E841-52.

4. Henneberg WS, Nilsson BL. Acute pediatric pain, review Curr Anesth Crit Care. 2007;18:126-34.

5. Lonnqvist PA, Morton NS. Postoperative analgesia in infants and children. Br J Anaesth. 2005;95(1):59-68.

6. Kim EM, Lee JR, Koo BN, Im YJ, Oh HJ, Lee JH. Analgesic efficacy of caudal dexamethasone combined with ropivacaine in children undergoing orchiopexy. $\mathrm{Br} J$ Anaesth. 2014;112(5):885-91.

7. Salami OF, Amanor-Boadu SD, Eyelade OR, Olateju SO. Effects of low-dose intravenous dexamethasone combined with caudal analgesia on post-herniotomy pain. Niger Postgrad Med J. 2017;24(4):230-5.

8. Silvani P, Camporesi A, Agostino MR, Salvo I. Caudal anesthesia in pediatrics: An update. Minerva Anestesiol. 2006;72:453-9.

9. Taheri R, Shayeghi S, Razavi SS, Sadeghi A, Ghabili K Ghojazadeh $\mathrm{M}$, et al. Efficacy of bupivacaine-neostigmine and bupivacaine-tramadol in caudal block in pediatric inguinal herniorrhaphy. Paediatr Anaesth. 2010;20:866-72.

10. Chong MA, Szoke DJ, Berbenetz NM, Lin C Dexamethasone as an adjuvant for caudal blockade in pediatric surgical patients: A Systematic Review and Metaanalysis. Anesth Analg. 2018;127(2):520-8.

11. Association of Paediatric Anaesthetists of Great Britain and Ireland. Good practice in postoperative and procedural pain management, 2nd edition. Paediatr Anaesth. 2012;22(suppl 1):1-79.

12. Chong MA, Berbenetz NM, Lin C, Singh S. Perineural versus intravenous dexamethasone as an adjuvant for peripheral nerve blocks: a systematic review and meta-analysis. Reg Anesth Pain Med. 2017;42(3):319-26.

13. De Oliveira Jr GS, Castro-Alves LJ, Ahmad S, Kendall MC, McCarthy RJ. Dexamethasone to prevent postoperative nausea and vomiting: an updated meta-analysis of randomized controlled trials. Anesthesia \& Analgesia. 2013 Jan 1;116(1):58-74.
14. Bangalore S, Toklu B, Wetterslev J. Complete versus culpritonly revascularization for ST-segment-elevation myocardial infarction and multivessel disease a metaanalysis and trial sequential analysis of randomized trials. Circ Cardiovasc Interv. 2015;8:e002142.

15. Johansson A, Hao J, Sjölund B. Local corticosteroid application blocks transmission in normal nociceptive Cfibres. Acta Anaesthesiol Scand. 1990;34(5):335-8.

16. Kim EM, Lee JR, Koo BN, Im YJ, Oh HJ, Lee JH. Analgesic efficacy of caudal dexamethasone combined with ropivacaine in children undergoing orchiopexy. $\mathrm{Br} \mathrm{J}$ Anaesth. 2014;112(5):885-91.

17. Bangash LR, Bangash L, Afzal F, Hussain S, Ali K. Comparison of caudal block alone with caudal block plus intravenous dexamethasone for postoperative analgesia in children undergoing orchidopexy under general anaesthesia. Biomedica. 2014;30(4):267-71.

18. Srinivasan S, Kandasamy KG. Analgesic efficacy of caudal dexamethasone combined with ropivacaine in children undergoing herniotomy. Indian J Appl Res. 2018;7(8):12832.

19. Hong J-Y, Han SW, Kim WO, Kim EJ, Kil HK. Effect of dexamethasone in combination with caudal analgesia on postoperative pain control in day case paediatric orchidopexy. Br J Anaesth. 2010;105(4):506-10.

20. Desmet M, Braems H, Reynvoet M, Plasschaert S, Van Cauwelaert J, et al. I.V. and perineural dexamethasone are equivalent in increasing the analgesic duration of a singleshot interscalene block with ropivacaine for shoulder surgery:a prospective, randomized, placebo-controlled study. Br J Anaesth. 2013;111(3):445-452.

21. Choi S, Rodseth R, McCartney CJL. Effects of dexamethsone as a local anaesthetic adjuvant for brachial plexus block: a systematic review and metanalysis of randomized controlled trials. $\mathrm{Br}$ J.Anaesth. 2014;112(3): 427-39. 